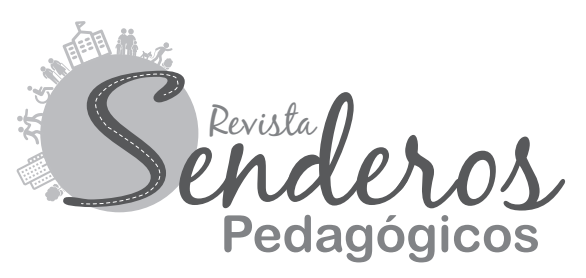

\title{
Reconfiguraciones televisivas: el tránsito actual de las audiencias ${ }^{1}$ \\ Television Reconfigurations: The Current Transit of the Audience
}

Autor:
Luis Humberto Rendón Arias ${ }^{2}$
Recibido: 14/03/2018
Aprobado: 26/04/2019

1. Resultado de Investigación tesis de Maestría. 2. Docente adscrito a la Facultad de Educación, programa de Licenciatura en Comunicación e Informática Educativa, Universidad Tecnológica de Pereira, Magíster en Comunicación Educativabetico@utp.edu.co

\section{Resumen}

Esta investigación buscó evidenciar las continuidades o rupturas en el proceso de consumo-producción en la recepción televisiva de los estudiantes de grado octavo de la Institución Educativa Jaime Salazar Robledo del barrio Tokio de la ciudad de Pereira. Se trabajó con una población objeto de estudio que pertenece a un grupo heterogéneo de sujetos (entre 11 y 15 años aproximadamente), de grado octavo de una institución educativa pública. La investigación buscó comprender cómo se presenta el proceso de videncia de los estudiantes a través de las diferentes mediaciones (micro y macro) planteadas por Orozco (2001). La temática a investigar se abordó desde un escenario donde se ubican las prácticas de visionado de la pantalla televisiva, para intentar construir un camino investigativo que diera cuenta desde el contexto regional de cuáles están siendo las incidencias de los procesos de recepción desde las micro y macromediaciones en el consumo televisivo de los estudiantes.

Metodológicamente se soportó en el protocolo de análisis / síntesis de información cualitativa de la maestría en Comunicación 
Educativa de la Universidad Tecnológica de Pereira. Para ello se utilizaron instrumentos cualitativos, entre los que se cuentan análisis de esquemas gráficos que se emplearon para dar cuenta de los tránsitos y rutinas televisivas del grupo de estudio, así como de las relaciones que se entablan con la pantalla. También se diseñó un formato de entrevista semiestructurada, la cual se adaptó de la metodología de observatorios de televisión propuesta por el investigador Orozco (2010), para abordar cualitativamente y con mayor profundidad el fenómeno a estudiar. Dentro de los resultados, se encontró que la audiencia abandona una zona de confort (los procesos de audiencia pasiva) y poco a poco se involucra en procesos más dinámicos. Por lo tanto, es una audiencia que empieza a meterse en la lógica de la globalización, esto es, a vincular nuevas pantallas a su videncia, a llevar a la cotidianidad lo que ven y a tener una visión crítica de las narrativas y de los mensajes televisivos. Se rompe la continuidad de la lógica que muchos investigadores presuponen debe darse, como una línea continua que va de la recepción pasiva a una completamente activa, donde la audiencia vehicula procesos de creación y de reconstrucción de realidades.

Palabras clave: audiencias televisivas, continuidad/ruptura, producción, consumo, macromediaciones, micromediaciones.

\begin{abstract}
This research aimed to show the continuities or ruptures in the consumptionproduction process in the television reception by students of the Educational Institution Jaime Salazar Robledo in the Tokyo neighborhood from Pereira (Colombia). The studied population belongs to a heterogeneous group of subjects from 11 to 15 years old in eighth grade of a public educational institution. The research sought to understand how the process of clairvoyance of students is presented through the micro and macro mediations proposed by Orozco (2001). This research was approached from a scenario in which the viewing practices of the television screen are located, to build an investigative path from a regional to identify the incidences of the reception processes from micro and macromediations in the television consumption of the students. To do this, the qualitative information analysis / synthesis protocol of the Master's Degree in Educational Communication of the Technological University of Pereira was used. This protocol included qualitative instruments such as the analysis of graphic schemes that were useful to describe the transit and television routines of the studied group, as well as the relationships that are established with the screen. A semi-structured interview format adapted from the television observatory methodology proposed by the researcher Orozco (2010) was also designed to address the study more deeply. One of the results of this research, is the capability of the audience to leave their comfort zone (passive audience processes) and gradually become involved in more dynamic processes such as globalization, that is, a new link from the screens to its clairvoyance (the ability to think and understand with insight) and to have a critical vision of narratives and television messages of what
\end{abstract}


they see every day. The logic presuppose by many researchers has changed and now is a continuous line that goes from passive reception to a fully active one, where the audience vehicle processes of creation and reconstruction of realities..

Keywords: television audiences, continuity / rupture, production, consumption, macromediations, micromediations

\section{Introducción}

El presente trabajo investigativo apuntó a distinguir relaciones de continuidad y ruptura que se pueden presentar entre consumo y producción en los procesos de recepción televisiva, por parte de estudiantes de grado octavo de la Institución Educativa Jaime Salazar Robledo (sede Tokio) en la ciudad de Pereira, como parte de un ejercicio social y cultural presente en los procesos actuales de recepción.

En un mundo cada vez más globalizado y donde la presencia mediática en la vida cotidiana es indiscutible, surgen dos medios que acaparan todo el poder y la relevancia mediática, social y cultural, que se extienden cada vez más: internet y, por supuesto, la televisión, la cual ha acompañado a la humanidad por casi setenta años (Williams, 1987, p.464). Es difícil discutir que la televisión está siendo un dispositivo altamente consumido, a través del cual las personas viven su cotidianidad. Este medio seduce, transforma y hasta educa; vehiculiza todas las problemáticas, configura incluso imaginarios y preferencias socioculturales.

La televisión es un gran medio de influencia para la opinión pública, es una especie de ventana al mundo para los sujetos de una sociedad. Esto ha hecho que sea objeto de innumerables estudios con perspectivas y miradas de análisis diversas, desde las positivistas hasta las apocalípticas ${ }^{3}$, aquellas que postulan la televisión como un problema o aquellas que la plantean como un elemento formador; sin embargo, muchos de estos estudios corren el riesgo de ser reduccionistas e impedir que se pueda dar cuenta de toda la potencialidad que este medio de comunicación posee actualmente.

En América Latina la relación que involucra estudios de medios y escuela se ha clasificado dentro de tres bloques: 
El primero, desarrollado desde la perspectiva de la corriente pedagógica de la imagen y la lectura crítica, se propone descifrar los contenidos, los lenguajes, las técnicas y las connotaciones ideológicas de los referentes televisivos (Quin, 1994). El segundo, enfocado en la concepción de educación para la recepción, explora las capacidades críticas de las audiencias para la lectura de las pantallas, centrando de esta forma el potencial en el televidente. (Fuenzalida, 1994). Y el tercer grupo, engloba los trabajos desarrollados por Olivera en el Brasil (1995) en el marco de la educomunicación y los trabajos de Orozco en México (1996) desde la relación educación, comunicación y educación para la televisión; este último grupo aborda la televisión desde tres dimensiones: los referentes televisivos, las características del medio y las mediaciones de los televidentes en relación con la televisión. (Bedoya, Valencia, Vélez y Rendón, 2015, p. 10).

Durante mucho tiempo, la manera en que se ha abordado la televisión con relación a sus audiencias, se ha movido entre esa dualidad mencionada, pero con los estudios que se vienen desarrollando en el campo de la educación y la comunicación, especialmente en América Latina, en lo que respecta a la videncia frente a las pantallas, puede decirse que la recepción funge como un factor de construcción de ciudadanía, además de ser un elemento multiplicador y constructor de cultura. Sirve tanto para entretener, educar, dormir, soñar, llorar, aburrirse, crear y simbolizar el mundo, entre otras. Lo cierto es que "las pantallas están en la vida cotidiana y a estas les cumplimos citas, les rendimos culto”, como lo afirma Rincón (2001, p.94).

Aun así, hay que dejar claro que el proceso de recepción no pasa, solamente, por entender que su materia prima son los contenidos, sino que son además formas culturales que median necesidades sociales y rituales de identidad. Hoy la globalización ha empezado a modificar la manera en que se hace la televisión y, por supuesto, la manera en que se consume la misma, las tecnologías de la información y la comunicación constituyen un potencial que está transformando las relaciones dadas entre productores, emisores y quienes recepcionan.

Orozco (2012), plantea que "la nueva "condición comunicacional” permite pasar de ser audiencias y lectores esencialmente receptores a ser "comunicantes": emisores e informantes ciudadanos, en una permanente interlocución con todos los que participan” (p. 16). En este orden de ideas, la recepción llevada a cabo por la mediación de la pantalla se vuelve simbólica como quiera que las audiencias, desde lo propuesto por Orozco en sus múltiples investigaciones, ya no recepcionan de manera pasiva los contenidos que circulan por la televisión, sino que se enfrentan a los mismos de una manera interactiva, genera resistencias, resignifica e interpela contenidos, y crea nuevas estéticas y nuevos sentidos, como ocurre por ejemplo con la transmediación. 
Cabe destacar que, a este escenario, lo nutre una nueva e interesante figura: la categoría del "prosumidor" (Lenderman y Sánchez, 2008, p. 178), que es aquel que abandona el estatus de receptor o espectador y es capaz de producir en esta cultura transformada de interactividad y convergencia tecnológica. Esto permite una reconfiguración del proceso de estar frente a las pantallas y lo abre a nuevos horizontes, esto enriquece el proceso y le otorga al televidente unas funciones propias de resistencia y creación que por supuesto desembocan en un rol mucho más activo y propositivo.

En síntesis, lo que permiten entender estas trayectorias y características de la audiencia junto con sus procesos de recepción es que existen unos límites porosos, unas rupturas y continuidades, que pueden llegar a convertirse en insumos muy interesantes de investigar y que contribuyen de manera importante a ampliar lo que este campo investigativo ha venido teorizando frente al tema. Esto, como quiera que la aparición de las audiencias productoras no implica necesariamente la desaparición de las anteriores formas, sino que lo que se genera es una conjunción de las tres formas (audiencias receptoras, consumidoras y productoras).

\section{Videncias múltiples: audiencias, recepciones y mediaciones}

El marco donde se desenvolvió esta investigación se encuentra ubicado dentro de las investigaciones del campo de la comunicación educativa y la educación para la televisión en América Latina; este campo de estudio ha trabajado la importancia de la televisión y sus diversas mediaciones como un ámbito en constante desarrollo. Desde sus enunciados, se supera la postura que señala a las audiencias televisivas como únicamente consumidoras y dóciles para la manipulación, y se las engloba dentro de la perspectiva de ciudadanos activos que trascienden su condición y devienen en productores respecto de los medios con los que interactúan; esto es la producción material y simbólica con las pantallas (Orozco, 1996, 70).

Las audiencias, contrario a lo que se creía décadas atrás, no son entes que recepcionan de manera pasiva; por ejemplo, a partir de la década de los 40, investigadores como Lasswell y Lazarsfeld 4 se preocuparon por conocer los efectos de los medios de comunicación en la audiencia, estudiando el poder que los mensajes tenían en los receptores, desde diversas esferas. Dichos mensajes tenían como fin ejercer control y generar patrones de conducta en quienes

\footnotetext{
4. Mass Communication Research (Investigación de los Medios Masivos de Comunicación). Esta corriente tiene entre sus objetivos primordiales analizar los efectos sociales, culturales y psicológicos de los mensajes que se pasaban por los medios masivos de comunicación, (mass media) y las reacciones que el público tenía frente a contenidos mediáticos con el fin de poder conducir el comportamiento de las masas.
} 
los recepcionaban. Estos estudios de manera implícita contribuyeron a que se fuese delimitando conceptualmente a la audiencia, aunque debe decirse que su naturaleza permanecía aún sin cuestionarse.

A medida que el tiempo fue transcurriendo, esta concepción fue evolucionando; unas décadas después la teoría de usos y gratificaciones comenzó a preocuparse por el consumidor o receptor, más que por los mensajes mismos ${ }^{5}$, y demostró como las audiencias usaban y sacaban provecho de los medios para satisfacer sus propias necesidades, y elaborar así una construcción propia de la realidad social que los circundaba. Estos estudios tendían a analizar, más allá del contenido de los medios, a la audiencia como sujetos parcialmente activos.

Posteriormente, los estudios culturales surgieron como un campo de investigación que agrupó iniciativas interdisciplinarias para analizar la manera de producir y/o crear significados, así como para estudiar los discursos que regulan las prácticas de la sociedad, y que revelan el papel que representa el poder en las actividades cotidianas. Los estudios culturales dan apertura así, al análisis de la codificación/ decodificación, que será el punto de partida para investigaciones significativas sobre la recepción, que la sitúa como parte de la vida cotidiana. Fue así como esta teoría estudió programas populares de televisión para desentrañar las ideologías que se hallaban al interior. Según esto, los grados de entendimiento estarían en el intercambio comunicativo que se pudiera dar entre quien codifica y produce los mensajes y quien decodifica y recepciona los mismos (Méndez, 2004, p. 161).

Los estudios actuales coinciden en reconocer que las audiencias llevan a cabo procesos donde entran en juego múltiples mediaciones que son de tipo social, cultural e histórico, las cuales interactúan con los contenidos televisivos, de cuyo resultado emergen resistencias, oposiciones y reconstrucción de realidades. De esta manera, el receptor adquiere un rol protagónico y puede desarrollar la capacidad para crear, recrear y negociar con los contenidos, lo que lo ubica en una perspectiva activa y protagónica de sus televidencias ${ }^{6}$. Bajo la anterior premisa, se aborda entonces, el concepto de audiencia que define Orozco:

5. Esta teoría tiene como punto de partida el consumidor, pues considera que importa más la función como experiencia directa con los medios y asume a los miembros del público como usuarios activos de los contenidos mediáticos, más que individuos pasivos que son influidos por ellos. Afirma esta teoría que los miembros del público hacen uso de mensajes y que es la utilización de los mismos la que interviene en el proceso del efecto.

6. La televidencia para Orozco, es la interacción específica con el referente televisivo. Implica la definición compleja de recepción, pero en referencia solamente a la televisión. 
Audiencia es aquí asumida como conjunto segmentado a partir de sus interacciones mediáticas de sujetos sociales, activos e interactivos, que no dejan de ser lo que son mientras entablan alguna relación siempre situada con el referente mediático, sea esta directa, indirecta o diferida. (Orozco, 2007, p.23)

Desde la perspectiva del autor mexicano, las audiencias son sujetos comunicantes, que son capaces de realizar televidencias inteligentes, con capacidad crítica y productiva de los contenidos televisivos, desde donde también adquieren identidades y producen sentido, como quiera que pueden llegar a disentir y organizarse para hacer valer sus derechos. Vista así la audiencia, tiene un enorme potencial en su relación con los medios, pero de acuerdo con Orozco, no por ello los receptores van a abandonar sus prácticas de diversión y entretenimiento que son primarias- pues siempre estará dada la relación espectacular con lo mediático-, sino que esta otra posibilidad de las audiencias, les permite ser sujetos autónomos, que pueden tomar distancia de los medios y de sus mensajes, o utilizarlos con sentidos totalmente opuestos a la lógica con que se crearon.

La televisión ha posibilitado en la audiencia procesos de interlocución, reconocimientos y elementos expresivos que Orozco (2007) califica como un nuevo status y, con esto, el medio deja de ser meramente un referente, para adquirir el rol de vehículo expresivo, por lo que las audiencias van a llevar a cabo procesos de agenciamiento particulares. Por esta razón, el autor determina que ser audiencia hoy significa tres cosas: Primero, "una transformación sustancial de su estructuración (...)”; segundo, “modifica el vínculo fundamental entre los sujetos sociales con su entorno, con los acontecimientos y fuentes tradicionales de información (...)"; y, tercero, "trastoca los limites espacio temporales del intercambio societal". (p.24).

Lo que deja claro este breve recorrido por la audiencia es precisamente que se puede reconocer que no hay una sola forma de ser audiencia como se nos quiso hacer creer en el pasado. La diversidad, multiplicidad, complejidad y versatilidad que han develado los estudios sobre la forma de concebir la audiencia permite pensar diferentes estrategias de comunicación para su conquista. Pero estas estrategias deben equiparar esa complejidad y abordar tanto sus prácticas de diversión y entretenimiento primarias (obedeciendo al carácter espectacular del medio), como la posibilidad de desarrollar sujetos autónomos, que pueden tomar distancia de los medios y de sus mensajes. De manera que ese aspecto lúdico que persiguen las audiencias y que antes se asociaba a su pasividad y maleabilidad, no excluye el que sean sujetos activos, abiertos a propuestas pedagógicas más complejas o a iniciativas que generen una educación crítica para la recepción. 
Bajo la anterior premisa, Barbero y Téllez (2006) señalan que a la hora de pensar en las audiencias hay que tener en cuenta "cómo los grupos compiten por la apropiación del producto social, organizan su distinción como sujetos individuales y colectivos, y se integran intercambiando significados, compartiendo el sentido mediante rituales cotidianos" (p.6o).

\section{Recepción: el mundo particular de las mediaciones}

De acuerdo con lo que se ha venido planteando líneas atrás, las audiencias son sujetos activos que despliegan procesos y mecanismos diversos para hacer recepción. Esta:

(...) no puede entenderse como mero recibimiento, sino como una interacción, siempre mediada desde diversas fuentes y contextualizada material, cognitiva y emocionalmente, que se despliega a lo largo de un proceso complejo situado en varios escenarios y que incluye estrategias y negociaciones de los sujetos con el referente mediático de la que resultan apropiaciones variadas que van desde la mera reproducción hasta la resistencia y la contestación (Orozco, 2007, p. 23).

En este escenario, la idea de la mediación resulta trascendental, pues allí se encuentra imbricado el margen que tienen las audiencias ya sea para su liberación o su docilidad. La mediación abordada desde el plano de la recepción permite entender la interacción entre la programación televisiva y sus audiencias. Es en la mediación donde se construye el sentido de la comunicación, y esto está dado más en el plano de la recepción que en el de la emisión, porque en el transcurso de la recepción se cuenta con cierta licencia para transformar el sentido de los contenidos. Fiske (1987) argumentaba que el conflicto dado entre producción y recepción no se hallaba en el texto presentado, sino en las características de la audiencia, observar menos los programas y más a las audiencias dado que allí es finalmente donde se generan los significados.

Las mediaciones pueden tener distintos orígenes y fuentes: los sujetos sociales, por ejemplo, con su historia de vida y sus características culturales, poseen un número importante de ellas. Todo el discurso televisivo también ha construido mediaciones relevantes desde donde se ha nutrido la recepción; otras son producto de la negociación entre la audiencia y el medio televisivo y, las hay, que surgen de instituciones y contextos particulares donde se desenvuelven las audiencias. En esta especie de juego se puede visualizar qué logran los medios y qué logran apropiar, negociar o rechazar las audiencias. 
En el caso concreto de la televisión, se puede hablar de "televidencias" que como se ha venido mencionando, son contratos de videncia que se crean entre el medio televisivo y su audiencia y son actividades que se realizan al interactuar con la televisión como: ver, escuchar, percibir, sentir, etc. Tales actividades son objeto de mediaciones y siempre estarán situadas y contextuadas (Orozco, 2003, p. 9). Ese proceso se da en dos momentos diferenciados: micromediaciones y macromediaciones.

Micromediaciones: aparecen aquí como un primer aglomerado de mediaciones, derivado del ámbito individual de aquellos sujetos, que hemos venido denominando sujetos-audiencia, las cuales tienen que ver con características propias, como el nivel educativo, el desarrollo cognoscitivo, la madurez emocional, el ámbito laboral, las vivencias, los deseos, las sensibilidades, y demás elementos que le otorgan a cada individuo su especificidad (sujetos particulares) y ejercen mediaciones que llevan a distinguir particulares estrategias televisivas y concretizar contratos de videncia. "La televidencia por más individualizada que parezca, es un proceso altamente culturizado, en tanto que la sobrevivencia supone tener grupos de interlocución en cuya consonancia se experimenta y califica lo vivido" (Orozco, 2007, p. 40). El autor menciona dos tipos de televidencias: de primer y segundo orden.

Televidencias de primer orden: este tipo de televidencia surge mientras la audiencia y el proceso de videncia se originan en la interacción con la pantalla (programas televisivos) y se decodifica el mensaje de acuerdo con unas características psicológicas y a un nivel cultural particular del sujeto que asume una videncia. Los sujetos en esta instancia pueden llegar a apropiar o a resistir diversos programas televisivos, con o sin intervención de otros sujetos. Aquí aparece lo que se podría denominar como una videncia primaria, puesto que implica un proceso inicial, resultante de ritualidades televisivas y de decisiones previas que se han podido tomar antes de estar frente al televisor.

Televidencia de segundo orden: las televidencias de segundo orden no se supeditan solo a la pantalla, van más allá y, quizá por estas características, adquieren un rótulo relevante. Se empiezan a gestar después de haber visto algún referente televisivo (programa) y haberse llevado a otros contextos, escenarios y con otros sujetos: "ocurre un contacto que no es directo ni físico (audiovisual) con la imagen y el relato televisivo, sino "resonante" (Orozco, 2007, p. 45), donde los sujetos-audiencia reproducen, renegocian y recrean el tiempo que reviven los distintos referentes televisivos. 
Este tipo de televidencias pueden desarrollarse en cualquier escenario, mientras se cumpla la condición de que exista el contacto del sujeto-audiencia con el referente televisivo; el sujeto-audiencia reproduce, renegocia y recrea, en escenarios y tiempos diferentes los referentes televisivos, que luego formarán parte del repertorio temático de conversación cotidiana o imágenes de representaciones sociales que este mismo consolida.

Macromediaciones: las macromediaciones connotan que no hay en esencia procesos de televidencia que sean puros, sino que existen además de posibles mediaciones individuales y contextuales, otras que de manera indirecta también ayudan al intercambio cotidiano de las audiencias con la televisión. Estos escenarios indirectos son:

Identidad e identidades: algunas de las identidades profundas que tienen las audiencias pueden hacerse presentes o salir a la luz de alguna manera en los actos televisivos. En este proceso, tales identidades se pueden reafirmar, reconvertir o reconfigurar, a partir de lo audiovisual y lo mediático. Estas afloran en las televidencias cuando hay interacciones con determinados referentes televisivos y esto permite, entonces, de alguna manera, entender algunos usos que tienen las audiencias respecto de la televisión.

Percepción y percepciones: se presentan como otra mediación donde entra en juego lo visual, auditivo, sensorial, simbólico, estético, emocional y lo racional. Elementos que son una vía de múltiples interacciones frente a los referentes televisivos y conforman un proceso que Orozco denomina cognoscitivo-afectivosignificante y que, en última instancia, terminan siendo ideas para contextualizar las aspiraciones de la audiencia. Puesto que los referentes televisivos son susceptibles a diversas interpretaciones y percepciones, algunos segmentos de televisión que han sido diseñados para producir reacciones en la audiencia como por ejemplo el entretenimiento, terminan cumpliendo funciones para las cuales no han sido destinadas como educar, ayudar a formar conductas, seguir patrones etc. De esta manera, la audiencia va definiendo a su modo particular, los sentidos que da a la programación, que incluso muchas veces, controvierte los sentidos propuestos desde la emisión de acuerdo con Orozco (2007, p. 48).

Instituciones e institucionalidades: la televisión como institución social ofrece variedad de mediaciones, agendas ciudadanas, configuración de lo que debe ser relevante en el ámbito educativo, informativo, cultural y lúdico. Tal ejercicio se experimenta gracias a las actuales tecnologías, revoluciones que hallan en el mercado su principal criterio de transformación, pues desde allí se nutre y se expande la programación, gracias a variadas fusiones empresariales, cuyo 
fin es ampliar las audiencias y aumentar el rating. La televisión no es la única institución en la que las audiencias se desenvuelven. Existen otras instancias o instituciones que desde el radio de acción donde se configuran, también fungen como mediadoras.

Todo este andamiaje conceptual estructurado por Orozco, hace evidente cómo los fenómenos de televidencia se han hecho más profundos y densos, a partir de dos dinámicas básicas: la complejización del sujeto receptor y la multiplicidad del proceso de recepción.

\section{Enfoque metodológico: rituales televisivos e interpretación nodal}

Esta propuesta se ubicó en el paradigma cualitativo. Porque pretendió reconocer significados construidos en el fenómeno de estudio, su enfoque fue hermenéutico, ya que pretendió interpretar los significados que surgieron de las relaciones de los estudiantes a partir de su interacción con la televisión en su calidad de audiencia. La metodología cualitativa se refiere en su más amplio sentido a la investigación que produce datos descriptivos: las propias palabras de las personas, habladas o escritas, y la conducta observable. La metodología cuantitativa es más que un conjunto de técnicas para recoger datos, es un modo de encarar el mundo empírico (Taylor y Bogdan, 1986, p. 20).

\section{Fuentes de recolección de la información}

Las fuentes abordadas para el propósito de esta la investigación fueron de tipo primario: se trabajó con la población de estudiantes de grado octavo de la institución educativa Jaime Salazar Robledo, de la ciudad de Pereira. Estos estudiantes presentan unas características más o menos similares en lo que se refiere al contexto sociocultural y económico, familias monoparentales, en la mayoría de casos de estratos bajos las cuales no cuentan con formación educativa en los niveles superiores, pertenecen a una población en condición de reubicación que se ha construido a raíz de un reasentamiento de personas con problemáticas propias del fenómeno del desplazamiento, entre otras características.

\section{Instrumentos de recolección de información}

La información fue recolectada por medio de un formulario de entrevista, que se adaptó de la metodología para trabajar observatorios de televisión, que el investigador Guillermo Orozco propone. También se llevó a cabo un análisis de imágenes. Los datos fueron suministrados directamente por la población objeto que corresponde a un grupo heterogéneo de 50 estudiantes. 
Se hizo uso de diferentes técnicas. En primer lugar, se trabajó con los estudiantes las rutinas y frecuencias de videncia y, para ello, se recurrió a la construcción gráfica de imágenes representativas para trabajar análisis semiótico y simbólico del dibujo, de sus maneras particulares de ver televisión, además, de manera gráfica bosquejaron su programación televisiva favorita, (rutinas de videncia). A continuación, un ejemplo:

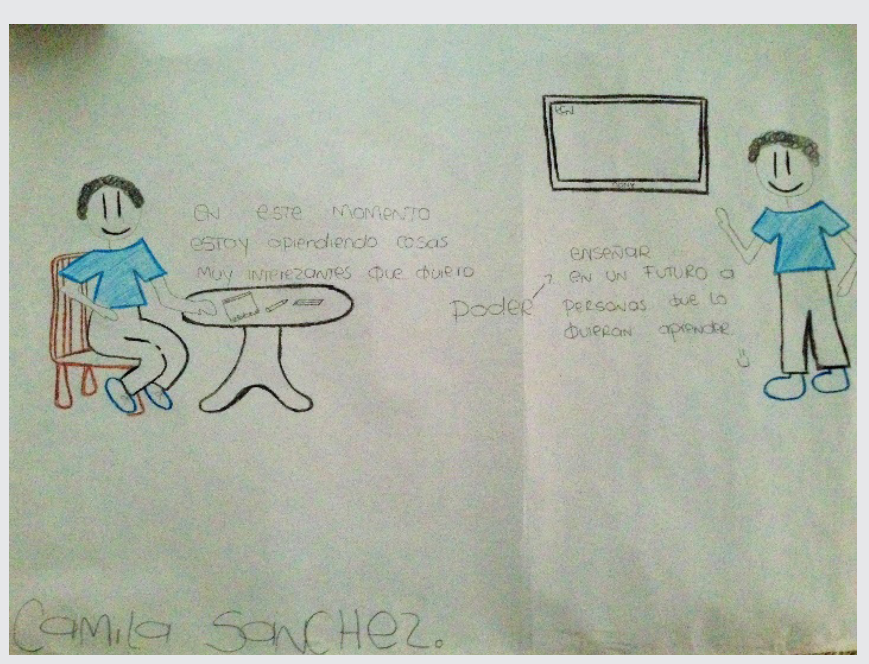

Figura 1. Dibujo frente a la tele

\section{Plantillas de análisis: en busca de los primeros indicios}

Esta plantilla se elaboró en hojas de papel; en ella los estudiantes iban consignando de manera espontánea sus rituales de ver televisión, dibujaban sus programas favoritos, esquematizaban también la rutina televisiva semanal, discriminándola por días, horas, y programas. Cada dibujo fue llevado a una matriz de análisis, el cual fue sometido a una descripción general de la imagen, donde de manera denotativa, se describió cada esquema y se detallaron los componentes de la imagen; para finalizar haciendo una descripción de carácter más connotativo, donde se resaltan los aspectos (índices) que se relacionaron con la pregunta de investigación o los objetivos que se plantearon.

En cuanto al proceso de la información, se trabajó a través del protocolo de análisis / síntesis de información cualitativa, que es una metodología que ha sido creada, adaptada y probada en diversas investigaciones, por la Maestría en Comunicación Educativa de la Universidad Tecnológica de Pereira. Método que 
permite construir y/o leer los datos de manera secuencial, con unas etapas que lo estructuran y que permiten acercarse a mayores grados de abstracción en la investigación. En ese orden de ideas, se llevaron a cabo las siguientes etapas: (1. Estructuración, 2. Agrupación de primer orden. 3. Agrupación de segundo orden, 4. Agrupación de tercer orden, 5. Agrupación de cuarto orden, 6. Agrupación de quinto orden y, finalmente, Nominación nodal)

Etapa de agrupación de primer orden: selección de elementos significativos

Para el análisis de algunas preguntas de carácter abierto del formulario de entrevista, se tomaron las palabras clave o frases que tuvieran alguna relación con las categorías conceptuales y los objetivos propuestos. Inicialmente se escogieron las palabras o frases más significativas en el texto y se les asignó un color. Estos elementos se consignaron en una tabla en Word (Tabla 1). (A continuación, se consigna un ejemplo)

Tabla 1. Agrupación de primer orden. Preguntas abiertas asociadas a colores.

\begin{tabular}{|c|l|}
\hline Código & ¿Por qué ves televisión? \\
\hline 001 & Porque a veces me siento desparchado \\
\hline 002 & Porque a veces no hay nada que hacer \\
\hline 003 & Es el único entretenimiento \\
\hline 004 & Me gusta \\
\hline 005 & Las novelas me llaman la atención y me dejan en duda a veces \\
\hline 006 & Porque no hay nada más que hacer \\
\hline
\end{tabular}

Fuente: Elaboración propia.

Etapa de agrupación de segundo orden: agrupación de elementos significativos. Después de haber seleccionado las palabras relacionadas con la pregunta de investigación, es necesario agruparlas a partir de la distinción de un rasgo común. En este caso, se cuenta el número de veces que se repitió la palabra y al frente se consigna el número de repeticiones para tener un dato claro de la concurrencia de la palabra dentro de los formularios. Luego se realiza un listado de las palabras o frases que tienen relación con el objeto de estudio y se organiza en una rejilla (Tabla 2): 
Tabla 2. Agrupación de segundo orden: palabras claves y número de repeticiones

\begin{tabular}{|l|l|}
\hline \multicolumn{1}{|c|}{ Término } & \multicolumn{1}{|c|}{ Cantidad } \\
\hline Películas & 11 \\
Novelas & 13 \\
Muñecos & 14 \\
Todo & 6 \\
\hline
\end{tabular}

Fuente: Elaboración propia.

Etapa de agrupación de tercer orden: nominación de los grupos construidos

Luego de haber realizado las agrupaciones, se definió un término o palabra que tuviese alguna relación entre ellas, que tuviera, aunque distinta escritura, un significado semejante que contuviera la agrupación anterior. Estas palabras salieron de las categorías teóricas presentes en el marco teórico. En este caso se agrupan de acuerdo con géneros o a segmentaciones de programación que permitan cierta similitud, tal agrupación se empieza a organizar para llegar más adelante a construir nodos (Tabla 3):

Tabla 3.Agrupación de tercer orden: Palabras clave y nodos

\begin{tabular}{|l|c|}
\hline \multicolumn{1}{|c|}{ Término } & Cantidad \\
\hline $\begin{array}{l}\text { Novelas- La rosa de Guadalupe- Floreceita- Av Brasil- Doctor Mata- } \\
\text { La selección- La playita- Tu Voz estéreo- Kick Buttowsky- Winnie } \\
\text { Pooh- Phineas y Fer- El Chavo- hora de aventura }\end{array}$ & 21 \\
\hline
\end{tabular}

Fuente: Elaboración propia

Etapa de agrupación de cuarto orden: nominación de los grupos construidos

En este punto se pretende empezar a elevar las anteriores agrupaciones a mayores niveles de abstracción; para eso se nominaron varias agrupaciones en unas categorías las cuales se denominaron con términos extraídos del marco teórico. Esto, para establecer relaciones entre ellas y, determinar si es pertinente contener tales términos o, por el contrario, recurrir a otras categorías diferentes (Tabla 4). 
Tabla 4. Agrupación de cuarto orden en categorías

\begin{tabular}{|c|l|c|}
\hline Nombres & \multicolumn{1}{|c|}{ Término } & Cantidad \\
\hline Diversión & $\begin{array}{l}\text { Entretiene- Desaburre- Desestresa- Divierte- No } \\
\text { hay nada más que hacer- Desparche }\end{array}$ & 36 \\
\hline Aprendizaje & Me gusta aprender- Enseña & 5 \\
\hline
\end{tabular}

Fuente: Elaboración propia

Etapa de agrupación de quinto orden: agrupación de elementos significativos

Tras haber realizado las agrupaciones nominales anteriores de cuarto orden, se optó por tomar un concepto que a su vez pudiera también contener la agrupación de cuarto orden. Aquí la asociación se desarrolló en términos más precisos, de acuerdo con las categorías conceptuales, por medio de una secuencia lógica que permitió depurar el formulario y, de esta manera, se alcanzó una mayor concentración del dato, mayor claridad y distinción de algunas dispersiones resultantes.

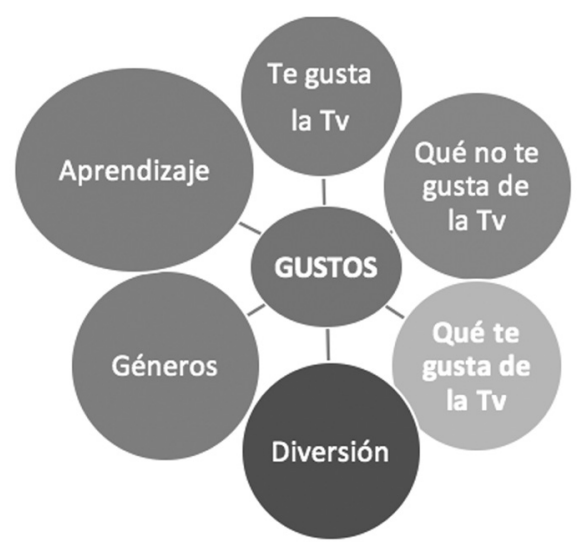

Figura 2. Agrupación de elementos significativos

Nominación nodal: habiendo reunido todas las relaciones nodales, se procedió a trabajar los resultados a manera de agrupación final, para ello, se tomaron las agrupaciones que hicieran parte de la subcategoría micromediaciones, se reunieron con un signo (+) hasta completar las que se pudieran vincular a esta 
nominación. Esto acercó más a las categorías teóricas del trabajo de investigación, y permitió construir resultados más concretos, teóricamente hablando (Figura 3): Micro mediaciones de primer orden

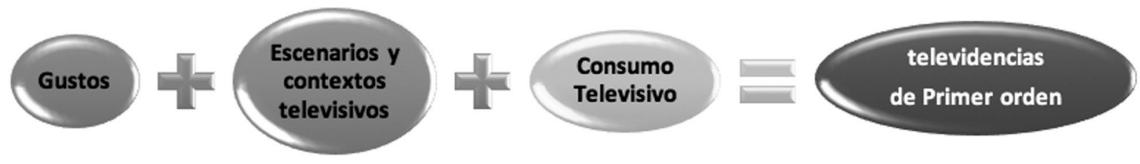

Figura 3. Televidencias de primer orden

\section{Apuntes sobre las micromediaciones y macromediaciones}

Retomando las ideas centrales de Guillermo Orozco (2007), en el ámbito de las mediaciones, aparecieron en el proceso de recepción televisiva de los estudiantes de la Institución Educativa Jaime Salazar Robledo, una serie de mediaciones que si bien provienen del ámbito individual, no se hallan desconectadas de otros procesos de vinculación grupal, pues permiten construir contratos en los que se vinculan características particulares de los sujetos con relación al acto de estar frente a la pantalla. Pero, que además de caracterizarse en lo subjetivo, también se sitúan en un contexto de diálogo con las elaboraciones de otros sujetos (familiares, amigos, pares, entre otros); esto implica que la negociación, la apropiación y la reproducción del contenido televisivo debe darse en el momento justo del acto del visionado. También va a repercutir en lo que se construye con la otredad, es decir, de su trascendencia en cualquier proceso comunicativo.

Bajo este lente, se esquematiza un panorama desde las televidencias de primer y segundo orden, para determinar las videncias que están desarrollando los estudiantes. Desde la caracterización de las Televidencias de primer orden, se detallan las rutinas concretas respecto al consumo televisivo, reflejados en los bloques de programación, los cuales connotan las posibilidades desde donde representan su realidad y la forma de relación de consumo mediático.

Lo visto a lo largo de la construcción del dato mostró, desde las formas de consumir televisión, programas particulares, canales específicos, horarios fijos, mediaciones y negociaciones, frente a los que los estudiantes desplegaron hábitos y costumbres, que terminaron convirtiéndose en estrategias y ritualidades televisivas propias.

La audiencia discrimina a su vez géneros, programas, canales y personajes favoritos, así como la temporalidad del consumo televisivo, esto da cuenta de las 
predisposiciones, posicionamientos y gratificaciones que los estudiantes tienen, lo que termina convirtiéndose en un tiempo de eminente gozo, pues establece la temporalidad de ocio que está ganando la televisión en esta población. Esto se bosqueja en géneros que se volvieron muy recurrentes en el análisis de la información a la hora de realizar la videncia.

De esta manera, películas, novelas, muñecos (caricaturas) y noticias son los grandes bloques de programación que emergieron como categorías de consumo, los cuales contienen los programas favoritos (programas infantiles, de novelas o programas de deporte), que pasan por dos tópicos importantes: la programación de dibujos animados, en consonancia con los canales de predilección, y las telenovelas que también se convierten en una franja importante de programación de los canales nacionales, también, un porcentaje significativo de programas de entretenimiento y deportes. Estos elementos conforman la porción total de la programación que es de la predilección y que consideran significativa los estudiantes indagados.

Poca evidencia resultó de una programación de carácter más cultural o educativo, o que denote un carácter distinto que llevara a este estudio a mirar posibles imponderables dentro de la investigación.

En cuanto a los personajes favoritos de los estudiantes, (Kick Buttowsky, Homero y Cristiano Ronaldo) el espectro está, como era de suponerse, dentro de los géneros de dibujos animados, las novelas, las películas y el fútbol. Sin embargo, los porcentajes que aparecen en las etapas de la construcción del dato no muestran un número significativo y no se impusieron como datos fuertes, por lo que se hizo necesario enmarcarlos en unos bloques que si fueron muy fuertes en el dato, como las categorías señaladas de dibujos animados, novelas, películas.

Estos referentes terminan por convertirse en patrones que se van configurando en estereotipos que la televisión ayuda a construir en la concepción particular de los televidentes, y que se interiorizan y se expresan a la hora de la identificación con la televisión y sus referentes; estos terminan siendo parte sustancial de procesos de comunicación. Todo lo anterior, está vinculado al ámbito temporal en que la misma población de estudio se desenvuelve.

Como lo señalaron los datos, las horas de la tarde y los fines de semana son los espacios de mayor consumo televisivo, con un carácter eminentemente recreativo. Puesto que no se hallaron muestras significativas por parte de la población de quebrantar estas lógicas que perfilan audiencias, por ejemplo, con indicios de optar por una programación diferente. Dentro de los parámetros que delimitan 
las frecuencias y rutinas televisivas, también aparecen los espacios cotidianos donde se lleva a cabo la videncia: la sala y el cuarto con un $40 \%$ de preferencia, son los espacios privilegiados para cumplirle la cita a la pantalla.

Este espacio de mediación que se da en la intimidad de los sujetos audiencia y que se presenta en lo privado, (aunque intervengan otros actores padres, hermanos y amigos), son en esencia flujos de consumo particularizados que se sincronizan de acuerdo con los diversos contratos que suscriben los estudiantes con el medio y la programación, y que hacen parte del mundo de las micromediaciones, que tienen lugar cuando el sujeto está frente a la pantalla provisto de su "arsenal simbólico".

El grupo de estudio evidenció ciertas razones y justificaciones para privilegiar la programación que consume. Dentro de estas sobresalen la justificación del entretenimiento y la gratificación que existe al acercarse a la pantalla, pues siempre estar frente al televisor proporciona sensaciones de diversión y placer al receptor, y es quizás una de las razones más poderosas para que siga siendo un medio tan contundente en nuestra época. Además, aparece otra idea vinculada con las escasas posibilidades u opciones de satisfacer la dimensión lúdica de los estudiantes, con otras actividades diversas a lo asociado con la pantalla: "no hay nada más que hacer", es una respuesta bastante común a la hora de argumentar el hecho de estar frente al televisor o al hecho de privilegiar lo que ven. Las justificaciones que destacan factores de enseñanza - aprendizaje son muy bajos, lo que sigue confirmando la premisa de que esencialmente los medios de comunicación y, en este caso específico, los de las pantallas, cumplen la función esencial de entretener.

El acto de ver televisión se sigue configurando en una rutina para los estudiantes: de acuerdo con las primeras videncias, se pueden distinguir particulares estrategias televisivas y sus formas de concretizar contratos de videncia, plasmados en el tipo de programación preferida en sus diferentes géneros, personajes de identificación, filiación de gustos, canales de predilección y no predilección, relación con la programación nacional e internacional. Las anteriores ideas dan una caracterización básica de la relación sujeto - pantalla, aquí el estudiante enfrenta su subjetividad con lo programático. Y para esta especie de disputa simbólica, el receptor cuenta con sus construcciones cognitivas, sociales y culturales; la televisión en cambio, con sus franjas, sus persuasiones y el juego de la conquista.

De este encuentro resultan reapropiaciones, rutinas y frecuencias de uso que construyen un perfil para esta población de manera que, como lo reitera Orozco 
(1989, p.40), la decisión sobre qué programa ver o a qué hora sentarse a ver televisión no son necesariamente actos aislados de televidentes individuales, también responden a patrones para ver televisión.

En lo que respecta a las televidencias de segundo orden, estas se gestan después de haber visto algún referente televisivo (programa) y haberse llevado a otros contextos, escenarios y otros sujetos, ya que los sujetos-audiencia reproducen, renegocian, recrean y reviven los distintos referentes televisivos.

Esto hace alusión a ciertas continuidades que resultan de lo que hay previa y posteriormente al contacto directo con el referente televisivo y adquieren un carácter de resonancia (van más allá del solo hecho de ver televisión). Están en el marco de las expresiones, discursos y socializaciones de los estudiantes, de acuerdo con lo que visionan en la pantalla. Como ya se ha reiterado al enfrentarnos a la televisión, estamos provistos de una suerte de mediaciones que le hacen aduana a la programación, donde se está llevando a cabo el ritual televisivo.

En este caso particular, la mediación que cumple la familia y los amigos es notoria, ya que permite distinguir qué están logrando los medios con sus discursos y qué logran apropiar, negociar o rechazar las audiencias. Este juego de negociación de las televidencias de segundo orden mostró a la familia y los amigos cercanos como los mediadores entre los estudiantes y los contenidos, pues son quienes ayudan a anclar los mensajes televisivos.

Es así como, por ejemplo, los estudiantes manifiestan de manera latente las recomendaciones sugeridas por estos actores, al igual que señalan que recurren a estos, en caso de dificultad con la decodificación del contenido. Incluso aún por fuera del espacio habitual para ver televisión (hogar), sigue manteniéndose la rutina televisiva con sus mediaciones en espacios externos, donde se sigue construyendo sentido y socializando.

No hay en esencia procesos de televidencia que sean puros, como lo menciona Orozco (2007), sino que más bien, existen posibles mediaciones individuales y contextuales y, en este caso particular, los acompañamientos son importantes para la población objeto de estudio, porque les permiten decodificar de mejor manera lo visto en la televisión. Pero también existen otras mediaciones que de forma indirecta ayudan al intercambio cotidiano de las audiencias con el medio. De esta manera, se van añadiendo al léxico particular expresiones como las que manifiestan los estudiantes y que las llevan a hacer parte de sus procesos de socialización particular. 
Contrario a lo que se pueda pensar a priori, o endilgar de negativo a la televisión en lo que respecta a imitación de patrones, conductas o modificación del vocabulario, en la audiencia, los resultados en este aspecto indican que, en grandes porcentajes, la mayoría de la población estudiada no tiene palabras favoritas para imitar de los personajes o la programación que consume. Esto reitera lo ya manifestado con antelación sobre la idea generalizada de que la televisión cumple inicialmente con la función de entretener.

Dentro de las prácticas comunicativas cotidianas de la población objeto de estudio, no se hallan imitaciones significativas que se apliquen en procesos comunicativos rutinarios; las pocas que aparecen están en el orden de la programación que expresan consumir, (dibujos animados, programas concurso y novelas), con muy bajos porcentajes de aplicación. Sigue presentándose de manera errónea la idea de que los receptores copian y asimilan para sí estereotipos televisivos, que luego de manera automática replican en sus estilos de vida.

Se pudo constatar que, en los principales lugares de la casa (habitación, sala), los estudiantes tienen pantallas para llevar acabo el acto de visionado; los hogares cuentan con diversidad de estas, lo cual sigue confirmando que la televisión es un producto de consumo de primera necesidad en los hogares.

Un hecho que puede destacarse es que la televisión por cable, en sus diferentes modalidades de consumo, está presente en las casas estudiadas, pues muchos canales de la predilección de los estudiantes obedecen a planes de televisión paga, dato no menor dado que la población se encuentra ubicada en estratos sociales identificados como bajos. Sin embargo, esto resalta la importancia que tiene la televisión en el gusto de las personas, pues adquirir estos canales implica un gasto extra dentro de las necesidades básicas, y seguramente el consumo de este servicio se viene imponiendo como una necesidad.

La televisión es un gran disparador de emociones, esto es una posibilidad que se da por descontada. La diversión sigue siendo condición sine qua non de las pantallas por las posibilidades lúdicas que entrega, las cuales los estudiantes manifiestan como condición satisfactoria de sus videncias. Estas gratificaciones contribuyen a esa dimensión emocional de cada sujeto frente a la pantalla, incluso aunque se diga que a las pantallas no se les otorga posibilidades para enseñar, los estudiantes la destacan como una opción fáctica dentro de su vinculación con la televisión, que permite desarrollar potencialidades desde lo formativo, la reflexión y la conciencia, abriendo canales desde las pantallas que se pueden aprovechar en el ámbito escolar. 
Las proyecciones de los sujetos sirven para detectar algunas de las identidades profundas que tienen las audiencias, las cuales pueden hacerse presentes en los actos televisivos, se reconfirman en el deseo de vivir experiencias presenciales en aquella programación que es de su predilección, y está dada en el hecho de sentirse representado en un personaje o pantalla.

Los pensamientos que construye la televisión pasan por simular la condición de los personajes que ven en la pantalla aquellos que reseñan en sus rutinas. Sentirse como ellos, actuar como ellos. Esto es una posibilidad de representación para los estudiantes, una especie de avatar, un yo virtual desde el deseo, pero representado en otro que suple aquello de lo que se carece en la realidad. Confrontarse cuando las escenas desbordan la realidad de la ficción y tener procesos de reflexión frente a lo que se está proyectando, son además otras facetas manifiestas y latentes de lo que la programación televisiva está generando en los estudiantes, más allá de lo que comúnmente se establece con la televisión en cuanto a deseos y emociones, que luego van a ser parte de su repertorio temático y de sus representaciones. Ese es el elemento clave en esta nueva forma de videncia, donde los sujetos sí construyen desde lo recepcionado.

Macromediaciones: La institución de la televisión, como ente social que también es modeladora en lo que al ámbito, informativo, cultural, lúdico y educativo respecta, propone modelos y parámetros que pueden ser encarnados como patrones o paradigmas a seguir, labor que la mediación con todos sus factores ayuda a combatir. En este escenario, las instituciones cumplen un rol determinante, especialmente, la familia. De manera particular, hay un aspecto que resulta curioso en los procesos de videncia de los estudiantes y tiene que ver con los padres, pues siempre han tenido preconcepciones, prejuicios o imaginarios con la televisión que de manera poco reflexiva trasladan a sus hijos y que se hicieron evidentes en el estudio.

Si bien los padres están otorgando vía libre para consumo de televisión, dada en una amplia libertad de consumo (pues como se dice reiteradamente en las reflexiones televisivas, la televisión entra sin pedir permiso a casa), solo se restringe lo relacionado con temas tabú (la pornografía y la violencia), pues este segmento se considera programación no apta para esta población y su respectiva segmentación de edad. Dos focos temáticos que la misma institución televisiva insiste en que deben estar bajo estrictos procesos de control y acompañamiento de parte de la institución familiar.

A veces en su afán de contribuir con la programación que ven sus hijos, simplemente prohíben cierto tipo de programas, o ejemplifican catastróficamente 
una situación de la pantalla, pero no ocurre que se dé una reflexión profunda acerca de lo que consumen sus hijos, o aprovechar la misma programación para tener conversaciones más pedagógicas con los referentes televisivos. Regularmente termina siendo un poco satanizada la televisión por falta de una adecuada educación mediática de los padres, y esto se vio reflejado en los análisis hechos para esta mediación.

En lo que respecta a las proyecciones de los estudiantes frente a su hipotética participación en la televisión, que implica el estar ante la televisión, no como aparato sino como un constructo de contenidos simbólicos comprendidos en narrativas audiovisuales, estéticas, mediaciones y construcciones de sentido, no se alejan de la tendencia que ha venido caracterizando sus videncias. De acuerdo con lo anterior, los estudiantes experimentan la necesidad de una extensión de la pantalla a los lugares de hábitat comunes y a sus espacios escolares como una necesidad que se impone desde las demandas lúdico-educativas para completar su videncia.

El reclamo en este sentido es unánime; en las pantallas circulan además de sus rutinas, sus proyecciones (avatar), sus deseos y sus estereotipos. Pero también el potencial pedagógico para ampliar la posibilidad de educar, como un dispositivo con carácter didáctico que brinda ventajas educativas y formadoras, y que puede llegar a las instituciones educativas.

Cuando se pretende vincular la televisión con la cotidianidad puede verse que la interacción con el medio televisivo trasciende más allá del acto de ver televisión, los mensajes que son emitidos por el medio, se trasladan a otros escenarios, escenarios que son precisamente el campo donde se reelaboran y se resemantizan los contenidos.

\section{Conclusiones}

Luego de caminar por los laberintos de la indagación de los procesos de recepción de las audiencias, es necesario centrarse ahora en los hallazgos que dejó la pregunta de investigación de este trabajo, y que tras una suerte de dilación se espera sea una construcción que siga aportando en lo que a la discusión de las audiencias se refiere, como quiera que da cuenta de un proceso empírico desde el cual nutrir lo que ya existe en el campo de la relación entre comunicación y educación.

Desde la lógica de la continuidad, los procesos de recepción televisiva presentan una constante evolución gracias al papel consciente y comprometido de las audiencias, marcado en sus evoluciones intelectuales y culturales, a la relevancia 
de las pantallas y, por supuesto, al desarrollo tecnológico presente en los múltiples dispositivos, que desplazó ya el acto de ver televisión desde las inmediaciones del hogar al plano virtual, y que en su creciente presencia de pantallas en la cotidianidad y en la facilidad de conexión a plataformas interactivas, reconstruye una continuidad o extensión de lo que es la realidad.

En este escenario de reconfiguración de la recepción, la continuidad de la audiencia se marca en el devenir que han tenido, pues abandonan una zona de confort (los procesos de audiencia pasiva) y poco a poco se involucran en procesos más dinámicos. Es una audiencia que empieza a meterse en la lógica de la globalización, esto es, a vincular nuevas pantallas a su videncia, a llevar a la cotidianidad lo que ven y a tener una visión crítica de las narrativas y de los mensajes televisivos. Están viendo en diversas pantallas lo que ha sido producido de manera original desde la pantalla habitual del monitor televisivo, y transmitido en una distinta, como es el caso de la programación televisiva vista a través de Internet, teléfonos móviles, tabletas o IPod.

La posibilidad de señalar una ruptura de sus videncias se halla en que aún no se insertan de manera contundente en las lógicas de comunidades virtuales que obedezcan a intereses particulares, ni muestran evidencias que los cataloguen como fanes, ni como prosumidores que replican en redes sociales lo que les deja la televisión. Aquí se presenta una ruptura, toda vez que se rompe la continuidad de la lógica que muchos investigadores presuponen debe darse, como una línea continua que va de la recepción pasiva a una completamente activa, donde la audiencia vehicula procesos de creación y de reconstrucción de realidades. Esta ruptura delinea otro tipo de recepción televisiva en los estudiantes, entendida no como audiencia pasiva, sino como una audiencia que trasciende esta categoría (la pasiva) y asume roles protagónicos básicos frente a su televidencia.

Es decir que llevan a cabo televidencias para satisfacer necesidades puntuales de gozo y placer, las asumen desde el sentido crítico, analítico o reflexivo, reconstruyen sus significaciones y las llevan a la cotidianidad, pero no se nota una extensión de lo visualizado en nuevas narrativas subjetivas, en procesos de comunidades agolpadas como comunidades de sentido, o de resignificación de derechos sociales. Tampoco se distinguen movilizaciones sociales en pro de una reivindicación o guiadas hacia la movilización de pensamiento.

Lo dicho hasta aquí por investigadores y analistas sobre las audiencias lleva a entender el proceso de recepción desde una continuidad idealista: audiencias receptoras, consumidoras y productoras, que debería ser el común tránsito de estas en la actualidad. Pero lo que este estudio ha mostrado es que tales 
audiencias ideales no se dan de manera automática, como lo plantean algunos teóricos, sino que son potencialidad, lo que en términos de Lévy (1999) sería la presencia en potencia: desde el escenario y la estructura de la web 2.0, están dadas las posibilidades para que se pueda generar; además hoy, las audiencias han reestructurado su estructura cognitiva, de tal manera que hablar de procesos multipantalla, procesos transmediales y estéticas narrativas son procesos apropiados y comunes en altos grados a la actual sociedad. Además, esto les otorga opciones de autonomía y deja expedito el camino a esa posibilidad.

Sin embargo, hay que ser claros: desde este grupo objeto de estudio no se ha dado el salto cualitativo a la prosumisión, estado ideal de las audiencias. Lo que hay son unos límites porosos, unas ciertas continuidades. Con esto se puede concluir que la aparición de unas audiencias no supone la desaparición de las otras, sino que se da una relación de continuidad, de conjunción de las diversas etapas por las que han transitado las audiencias; en ese recorrido se han reconfigurado, a la vez que adaptado a los contextos particulares donde se mueven, y adquiriendo unas características propias, que si bien no necesariamente tienen que ser las que se señalan como ideales, si se acercan a procesos de transformación cualitativos a la hora de asumir la televisión y de asumirse como audiencia.

Lo entregado por los datos mostró que hoy se da una sinergia entre los tipos de audiencia y sus procesos, la recepción pasiva puede verse en el solo acto de los estudiantes de estar en la pantalla satisfaciendo sus necesidades básicas de entretenimiento, sin que les interese llevar a cabo otros procesos. Pero también existen momentos donde median el acto televisivo desde el componente reflexivo y crítico, analizan situaciones, entienden valores e ideas que se les vehiculan por la televisión, están en la capacidad de juzgar una programación y luego ser capaces de trastocar su sentido en el acto comunicativo de su entorno cercano. Todas estas características del proceso de visionado indican como estas tres formas de las audiencias se amalgaman, se reconstruyen sin anularse una a la otra, por el contrario, son constitutivas de una nueva manera de videnciar las pantallas.

Otra forma de ver particularmente este juego de continuidad ruptura, tiene que ver con la participación, pues esta, históricamente fue vehiculada por un sistema que se referenciaba o traducía en cifras de rating, que daba cuenta de los hábitos de consumo. Este factor también presenta una disrupción porque la televisión como pantalla se encuentra interpelada y afectada por los nuevos hábitos de consumo de sus públicos, que van desde el consumo de meros espectadores a la producción de usuarios multitasking que se conectan a varios dispositivos. 
Otra línea para ver esta relación son sin duda los cambios de roles, que en lo que respecta a la televisión han trascendido de lo pasivo a lo activo, lo que representa una continuidad progresiva en la forma de asumirse subjetivamente frente a los contenidos; sin embargo, también existe una interesante ruptura, ahora se pasa de lo que es masivo a lo que es personal, es decir dispositivos con la cualidad de la portabilidad y la instantaneidad, para asumir los contenidos de manera personalizada y casi atomizada.

Y, es en esa lógica de la atomización, que se presenta otra ruptura frente a la idea de una audiencia que se asumió como colectiva durante mucho tiempo, y que solo se segmentó en franjas horarias y niveles etarios; ahora lo que se rompe es la concepción del usuario, pues elige todo el tiempo entre una oferta de contenido, que por demás está decir es bastante diversificada, lo que provoca fragmentación de audiencia, que deriva a su vez en una nueva colectivización. Se pasa de grandes colectivos de público a colectivos más pequeños que camuflan sus consumos.

Los procesos de televidencia de los estudiantes fluctúan, son a veces aleatorios gracias a las transformaciones y configuraciones que sobre ellos ejercen las mediaciones que surgen en la interacción del sujeto con otros y con el medio. Por esta razón, se concluye que los procesos de televidencia de los estudiantes no pueden enmarcarse en una identificación concreta y única, ni desde generalizaciones abarcables a todos los estudiantes, aun cuando pueden darse elementos similares como, por ejemplo, el visionado individual que más o menos se estandariza, así como el naciente interés en la convergencia de pantallas en este proceso de visionado e interacción, y la capacidad de decisión y participación en su relación con la televisión. Por último, es importante aludir a la trascendencia de lo visionado, en la medida en que estos están migrando hacia contextos como la institución educativa, el barrio y sus grupos de amigos, donde traen a colación evocaciones, recuerdos, anécdotas e ilustraciones a la cotidianidad de lo que vieron en la pantalla.

\section{Referencias}

Aguaded, J. y Díaz, R. (2008). La formación de telespectadores críticos en educación secundaria. Revista Latina de Comunicación Social. 63, 121-139. Recuperado el 11 de marzo de 2016, de http:/www.ull.es/publicaciones/ latina/_2008/12_19_Huelva/Aguaded.html.

Arrañaga, J. (2013). La demanda de televisión en multipantallas. Documentación de las Ciencias de la Información. 36, 191-208. Recuperado en: http://revistas. ucm.es/index.php/DCIN/article/view/42105/41528 
Barreda, M. (2014). La investigación sobre la atención durante el consumo de televisión. Historia y Comunicación Social. 18, 571-580. Recuperado en http:// revistas.ucm.es/index.php/HICS/article/view/43989

Bonilla, J. (2011). Re-visitando los estudios de recepción / audiencias en Colombia. Comunicación y sociedad, 16, 75-104.

Bourdieu, P. (1997). Sobre la Televisión. Barcelona: Anagrama.

Danta, R. (2009). TV y capitalización del tiempo de ocio: La programación como medio de producción. Revista Latina de Comunicación Social, 64, 572584. Recuperado el 15 de enero de 2016, de: http://www.revistalatina.org/o9/ art/47_846_ULEPICC_04/39Danta.html

Gabelas, J. y Lazo, C. (2008). Modos de intervención de los padres en el conflicto que supone el consumo de pantallas. Revista Latina de Comunicación Social, 63, 238-252. Recuperado el 15 de julio de 2014 en http://www.ull.es/ publicaciones/latina/_2008/19_25_Zaragoza/Gabelas_y_Marta.html.

González, C. y Fanjul, C (2009). Marcas televisivas. La gestión de la continuidad en el medio televisivo español. Revista Latina de Comunicación Social, 64, 894 - 908. Recuperado el 9 de abril de 2015 en http://www.revistalatinacs. org/o9/art/869_UJI/70_95_Gonzalez_y_Fanjul.html

Hernández, M. y Grandío, M. (2011). Narrativa crossmedia en el discurso televisivo de Ciencia Ficción. Estudio de Battlestar Galactica (2003-2010). Área abierta, 28, 1-20. Recuperado el 3 de marzo de 2016 de http://revistas. ucm.es/index.php/ARAB/article/view/ARAB1111130004A/4O3

Jacks, N. (2008). Estudios sobre la recepción televisiva y la identidad cultural. Comunicar, 30, 61- 65. Recuperado el 6 de julio de 2014 de: file://Users/ macpro/Downloads/Comunicar-30-Jacks-61-65.pdf

Jenkins, H. (2006). La cultura de la convergencia. Estados Unidos: Paidós.

Jensen, Klaus B (1998): News of the world. Londres: Routledge.

Lazo, C. (2005). Agentes mediadores y responsables del consumo infantil de televisión: familia, escuela y medios de comunicación. Comunicación y hombre, 1, 19-34.

Lazo, M. y Grandío, M. (2013). Análisis de la competencia audiovisual de la ciudadanía española en la dimensión de recepción y audiencia. Comunicación y Sociedad, 26, 114- 130.

Lenderman, M. y Sánchez, R. (2008). Marketing experiencial: la revolución de las marcas. Madrid: Esic.

Martín-Barbero, J. (2003). De los medios a las mediaciones: comunicación, cultura y hegemonía. Bogotá: Gustavo Gili. 
Martín-Barbero, J. (2012). Jesús Martín Barbero: yo no fui a buscar los efectos, sino los reconocimientos. En Bonilla, J., Cataño, M., Rincón, O., Zuluaga, J. De las audiencias contemplativas a los productores conectados. (21-39). Bogotá: Sello Editorial Javeriano.

Mazziotti, N. (2001). Los géneros en la televisión pública. En Rincón, O. (coord.), Televisión pública: del consumidor al ciudadano (179-207). Bogotá: Convenio Andrés Bello.

Méndez, A. (2004). Perspectivas sobre comunicación y sociedad. Valencia: Quiles.

Muñoz, H. (2011). Pereira imaginada 2009 - 2014: Anhelos y esperanzas de los pereiranos al ver los noticieros de la primera franja televisiva. Pereira: Universidad Tecnológica de Pereira. Recuperado de: http://repositorio.utp. edu.co/dspace/handle/11059/2632

Nivón E (coord) (2012). Voces Hibridas: Reflexiones en torno a la obra de García Canclini. México: siglo XXI.

Orozco, G. (1996). Televisión y audiencias: un enfoque cualitativo. Madrid: Ediciones de la Torre.

Orozco, G. (1997). Medios, audiencias y mediaciones. Comunicar, 8, 25-30. Recuperado el 6 de julio de 2014 de: http://www.redalyc.org/articulo. oa?id=15800806

Orozco, G. (1998). Hacia una pedagogía de la televidencia. Comunicación y Sociedad, 32, 169- 199.

Orozco, G. (2001). Audiencias, televisión y educación: una deconstrucción pedagógica de la «televidencia» y sus mediaciones. Revista Iberoamericana de Educación, 27, 165-175.

Orozco, G. (2003). Los estudios de recepcion: de un modo de investigar, a una moda, y de ahí a muchos modos. Intexto, 9, 1-13. Recuperado el 15 de julio de 2014, de: http://www.seer.ufrgs.br/intexto/article/viewFile/3629/4400

Orozco, G. (2007). Televisión, audiencias y educación. Bogotá: Norma.

Ortega A. y Rojas J. (2014) Recepción de la televisión educativa en niños y niñas de 7 a 10 años de edad del colegio Los Alpes de la localidad cuarta - San Cristóbal. Bogotá: Convenio Universidad Minuto de Dios y Universidad Tecnológica de Pereira. Recuperado de: http://repositorio.utp.edu.co/ dspace/bitstream/11059/5211/1/79145O77.pdf

Taylor, S. Y Bogdan, R. (1986). Introducción: ir hacia la gente. En Introducción a los métodos cualitativos de investigación. México: Paidós. pp 15-27. 
Rosique, G. (2014). El estudio de la recepción televisiva desde la perspectiva de la ciudadanía organizada. Historia y Comunicación Social. 18, 213-224. Recuperado en: http://revistas.ucm.es/index.php/HICS/article/view/44323

Scolari, C., Jiménez, M. y Guerrero, M. (2012). Narrativas transmedia en España. Comunicación y Sociedad. 25, 137-164.

Silva, A. (1992). Imaginarios urbanos, Bogotá y São Paulo: cultura y comunicación urbana en América Latina. Bogotá: Tercer Mundo Editores.

Torrecillas-Lacave, T. (2013). Los padres, ante el consumo televisivo de los hijos: Estilos de mediación. Revista Latina de Comunicación Social. 68, 27-54. Recuperado el 13 de mayo de 2015 de http://www.revistalatinacs.org/ 068/ paper /968_CEU/O2_Torrecillas.html

Vega, J.y Lafaurie, A. (2013). Observar TV: Un observatorio infantil de televisión para la interlocución de los niños. Comunicar, 40, 145-153. Recuperado de http://dx.doi.org/10.3916/C40-2013-03-05

Williams, T. (1987). Historia de la tecnología: desde 1900 a 1950. Madrid: Siglo XXI Editores. 